\title{
Effects of Weight Loss and Exercise on Apelin Serum Concentrations and Adipose Tissue Expression in Human Obesity
}

\author{
Joanna Krist ${ }^{a}$ Katharina Wieder ${ }^{a} \quad$ Nora Klöting $^{b} \quad$ Andreas Oberbach $^{c}$ \\ Susan Kralisch $^{a}$ Tobias Wiesner ${ }^{a}$ Michael R. Schönd Daniel Gärtner ${ }^{d}$ \\ Arne Dietrich $^{e}$ Edward Shang ${ }^{e}$ Tobias Lohmann ${ }^{f}$ Miriam Dreßler ${ }^{f}$ \\ Mathias Fasshauer ${ }^{a} \quad$ Michael Stumvoll $^{a}$ Matthias Blüher ${ }^{a}$ \\ ${ }^{a}$ Department of Medicine, University of Leipzig, ${ }^{b}$ Leipzig University Medical Center, IFB \\ Adiposity Diseases, Junior Research Group Animal Models, ' ${ }^{C}$ Department of Pediatric \\ Surgery, University of Leipzig, Leipzig, d Clinic of Visceral Surgery, Städtisches Klinikum \\ Karlsruhe, Karlsruhe, e Department of Surgery, University of Leipzig, Leipzig, ${ }^{f}$ Municipal \\ Clinic Dresden-Neustadt, Dresden, Germany
}

\section{Key Words}

Apelin · Visceral adipose tissue $\cdot$ Obesity $\cdot$ Insulin resistance $\cdot$ Adipokines

\begin{abstract}
Objective: Apelin is an adipokine which plays a role in the regulation of glucose homeostasis and may contribute to the link between increased adipose tissue mass and obesity related metabolic diseases. Here we investigate the role of omental and subcutaneous (SC) adipose tissue apelin and its receptor APJ mRNA expression in human obesity and test the hypothesis that changes in circulating apelin are associated with reduced fat mass in three weight loss intervention studies. Methods: Apelin serum concentration was measured in 740 individuals in a cross-sectional $(n=629)$ study including a subgroup $(n=161)$ for which omental and SC apelin mRNA expression has been analyzed and in three interventions: 12 weeks exercise $(n=60), 6$ months calorie-restricted diet $(n=19), 12$ months after bariatric surgery $(n=32)$. Results: Apelin mRNA is significantly higher expressed in adipose tissue of patients with type 2 diabetes and correlates with circulating apelin, BMI, body fat, C-reactive protein, and insulin sensitivity. Obesity surgery-induced weight loss causes a significant reduction in omental and SC apelin expression. All interventions led to significantly reduced apelin serum concentrations which significantly correlate with improved insulin sensitivity, independently of changes in BMI. Conclusions: Reduced apelin expression and serum concentration may contribute to improved insulin sensitivity beyond significant weight loss.
\end{abstract}


Krist et al.: Effects of Weight Loss and Exercise on Apelin Serum Concentrations and Adipose Tissue Expression in Human Obesity

\section{Introduction}

Apelin, a 36 amino-acid peptide and endogenous ligand of the G-protein-coupled receptor APJ receptor, has been identified in a variety of tissues, including the central nervous system, with high expression in the hypothalamus, stomach, heart, skeletal muscle, and white adipose tissue [1-3]. There are several active apelin forms including apelin-36, apelin-17, apelin-13, and the pyroglutamated form of apelin-13 [2]. Apelin and APJ mRNA are widely expressed in several rat and human tissues and play a role in the regulation of cardiovascular homeostastis, food intake, cell proliferation, and angiogenesis [1-4]. The cardiovascular system appears to be an important source of apelin since both apelin and its receptor are present in heart, large or small conduit vessels, and endothelial cells [4]. Since apelin is secreted from adipose tissue, it is considered an adipokine $[5,6]$. In the initial analysis of apelin gene-deficient mice, there was no obvious metabolic phenotype [7]. However, in subsequent studies, it has been found that apelin-null mice have impaired insulin sensitivity - an effect which could be reversed by administration of exogenous apelin [8]. As shown in $\mathrm{C}_{2} \mathrm{C}_{12}$ myotubes in vitro, improved insulin sensitivity upon apelin administration is due to direct effects on glucose uptake and intracellular insulin signaling [8].

However, with ageing apelin-knockout mice developed progressive impairment of cardiac contractility associated with systolic dysfunction, suggesting that apelin is crucial to maintain cardiac contractility in pressure overload and aging [7]. The observed changes in cardiac contractility were associated with concerted up-regulation of genes involved in extracellular matrix remodeling and muscle contraction [7]. It could also been recently demonstrated that hypoxia induces apelin expression both in endothelial and vascular smooth muscle cells mediated by the binding of HIF-1 to a HRE located within the first intron of the apelin gene [9].

Apelin serum concentration was shown to be higher in patients with obesity and insulin resistance [6]. Recently, higher apelin serum concentrations were found to be associated with liver cirrhosis both in rats and humans [10]. Moreover, treatment of rats with cirrhosis with an apelin receptor antagonist showed diminished hepatic fibrosis and loss of ascites [10]. Apelin has also been shown to inhibit insulin secretion in mice [11], suggesting a link between apelin and glucose homeostasis. Apelin serum concentrations correlate with hyperinsulinemia and obesity, suggesting that apelin may be another adipokine mediator of impaired adipose tissue function in obesity [6]. In addition, it has been demonstrated that apelin has a glucose-lowering effect being associated with enhanced glucose utilization in skeletal muscle and fat [12]. In obese and insulin-resistant mice, apelin restored glucose tolerance and increased glucose utilization [12]. The glucose-lowering effects seem to involve endothelial NO synthase, AMP-activated protein kinase, and Akt further suggesting that apelin might link obesity to insulin resistance, endothelial dysfunction, and cardiovascular disease. Very recently, Attané and coworkers [13] demonstrated that apelin treatment of high-fat dietinduced obese, insulin- resistant mice over 4 weeks improves the entire energy metabolism through increased mitochondrial biogenesis and tighter matching between fatty acid oxidation and the tricarboxylic acid cycle. Apelin could thus represent a promising treatment tool in the management of insulin resistance and impaired energy metabolism [12, 13].

Collectively, human and rodent data indicate that apelin influences glucose homeostasis and may contribute to the link between increased adipose tissue mass and obesity-related metabolic and inflammatory diseases. Interestingly, there are some inconsistent results regarding the effects of weight loss interventions in obese and insulin-resistant children and adults (reviewed in [2]). Here we test the hypothesis that reduced apelin mRNA expression in human adipose tissue contributes to reduced circulating apelin concentrations after bariatric surgery. In parallel to apelin, we measured mRNA expression of its receptor APJ in 
Krist et al.: Effects of Weight Loss and Exercise on Apelin Serum Concentrations and Adipose Tissue Expression in Human Obesity

Table 1. Effects of a standardized 12-week training intervention on anthropometric, metabolic, and hormonal parameters at baseline and after 12 weeks of intensive physical training in subjects with NGT, IGT, and T2D (Cohort 3)

\begin{tabular}{|c|c|c|c|c|c|c|}
\hline & \multicolumn{2}{|c|}{ NGT $(n=20)$} & \multicolumn{2}{|l|}{ IGT $(n=20)$} & \multicolumn{2}{|l|}{ T2D $(n=20)$} \\
\hline & baseline & $\begin{array}{l}\text { post inter- } \\
\text { vention }\end{array}$ & baseline & $\begin{array}{l}\text { post inter- } \\
\text { vention }\end{array}$ & baseline & $\begin{array}{l}\text { post inter- } \\
\text { vention }\end{array}$ \\
\hline Male/female & $9 / 11$ & & $9 / 11$ & & $11 / 9$ & \\
\hline Age, years & $32.8 \pm 2.5$ & & $56.0 \pm 3.6^{a}$ & & $53.1 \pm 1.5^{\mathrm{a}}$ & \\
\hline BMI, $\mathrm{kg} / \mathrm{m}^{2}$ & $24.3 \pm 0.3$ & $23.8 \pm 0.5$ & $29.8 \pm 0.9^{a}$ & $28.9 \pm 1.1$ & $31.4 \pm 0.7^{\mathrm{a}}$ & $30.5 \pm 1.0$ \\
\hline Fat mass, \% & $24.5 \pm 0.7$ & $22.8 \pm 0.5$ & $34.9 \pm 1.9^{a}$ & $32.6 \pm 1.7^{*}$ & $38.2 \pm 1.8^{\mathrm{a}}$ & $35.8 \pm 0.9^{*}$ \\
\hline $\mathrm{FPG}, \mathrm{mmol} / \mathrm{l}$ & $5.1 \pm 0.1$ & $5.2 \pm 0.2$ & $5.6 \pm 0.1$ & $5.3 \pm 0.2$ & $6.2 \pm 0.13^{a}$ & $5.9 \pm 0.2$ \\
\hline FPI, mmol/l & $66 \pm 8$ & $52 \pm 12$ & $695 \pm 110^{\mathrm{a}}$ & $317 \pm 59^{*}$ & $319 \pm 50^{\mathrm{a}}$ & $218 \pm 59 *$ \\
\hline 2h OGTT & $6.3 \pm 0.5$ & - & $9.5 \pm 1.2^{\mathrm{a}}$ & - & $13.4 \pm 2.3^{\mathrm{a}}$ & - \\
\hline WBGU, $\mu \mathrm{mol} / \mathrm{kg} / \mathrm{min}$ & $76 \pm 4$ & $89 \pm 9 *$ & $19 \pm 2^{\mathrm{a}}$ & $41 \pm 8^{*}$ & $21 \pm 2^{\mathrm{a}}$ & $37 \pm 6^{*}$ \\
\hline FFA $(\mathrm{mmol} / \mathrm{l})$ & $0.41 \pm 0.04$ & $0.35 \pm 0.04 *$ & $0.53 \pm 0.06^{\mathrm{a}}$ & $0.45 \pm 0.03^{*}$ & $0.56 \pm 0.06^{\mathrm{a}}$ & $0.49 \pm 0.05$ \\
\hline
\end{tabular}

FPG = Fasting plasma glucose; FPI = fasting plasma insulin, 2h OGTT, 2-hour plasma glucose of an oral glucose tolerance test; FFA $=$ free fatty acids. Data are expressed as mean \pm SEM. ${ }^{*} \mathrm{p}<0.05,{ }^{* *} \mathrm{p}<0.01$ compared to baseline. ${ }^{\mathrm{a}} \mathrm{p}<0.05$ compared to NGT group.

human omental and subcutaneous (SC) adipose tissue. In addition, we aim to dissect whether changes in apelin serum concentrations are primarily associated with improved insulin sensitivity or reduced body fat mass in the context of three weight loss intervention studies ( 6 months hypocaloric diet, 12 months after bariatric surgery, 12 weeks exercise program).

\section{Participants and Methods}

\section{Subjects}

We included five different cohorts, which have been previously reported in detail [14], with a total number of 740 individuals ( 401 women, 339 men) in our study of apelin serum concentration and adipose tissue mRNA expression. In brief, in cohort $1\left(\mathrm{n}=468\right.$, mean BMI $\left.31.9 \pm 6.1 \mathrm{~kg} / \mathrm{m}^{2}\right)$, we investigated apelin serum concentrations in relation to measures of obesity and glucose metabolism in a cross-sectional study. 468 Caucasian men $(n=220)$ and women $(n=248)$ have been consecutively recruited in the context of a study on insulin resistance at the Department of Medicine, University of Leipzig, to represent a wide range of obesity, insulin sensitivity, and glucose tolerance. The age ranged from 19 to 80 years and BMI from 17.1 to $79.1 \mathrm{~kg} / \mathrm{m}^{2}$. The study included 290 patients with type 2 diabetes (T2D) and 178 normal glucose tolerance (NGT) controls [14]. From these individuals, we selected 58 which could be matched for age, gender, and BMI into subgroups of NGT and T2D [14]. In cohort 2, we investigated apelin mRNA expression in paired omental and SC adipose tissue samples in addition to apelin serum concentrations in 161 patients (85 women, 76 men; mean BMI $30.8 \pm 6.7 \mathrm{~kg} / \mathrm{m}^{2}$ ) who underwent abdominal surgery for cholecystectomy, weight reduction surgery, abdominal injuries, or explorative laparotomy [14]. From these individuals, we selected 32 which could be matched for age, gender, and BMI (mean BMI $33.0 \pm 1.9 \mathrm{~kg} / \mathrm{m}^{2}$ ) into subgroups of NGT and T2D. Adipose tissue was immediately frozen in liquid nitrogen after explantation. Histologic analyses and measurement of macrophage count in adipose tissue was performed as previously described [15]. In addition, we investigated circulating apelin in response to a 12 -week intensive exercise intervention in 60 individuals (cohort 3) with a mean baseline BMI $28.1 \pm 0.8 \mathrm{~kg} / \mathrm{m}^{2}$, which have been divided into groups of NGT ( $\mathrm{n}=20$; 9 males, 11 females), impaired glucose tolerance (IGT; $n=20 n=20 ; 9$ males, 11 females), and T2D ( $n=20$; 11 males, 9 females) on the basis of a 75-gram oral glucose tolerance test (OGTT) according to the ADA criteria [16] (table 1). These 60 individuals were enrolled in $60 \mathrm{~min}$ of supervised physical training sessions 3 days per week as described previously [17]. 
Krist et al.: Effects of Weight Loss and Exercise on Apelin Serum Concentrations and Adipose Tissue Expression in Human Obesity

In addition, we measured circulating apelin before and 6 months after a calorie-restricted diet study (cohort $4, \mathrm{n}=19 ; 15$ women, 4 men; mean age: $49 \pm 2.71$ years). The mean baseline BMI was $36.4 \pm 1.2$ $\mathrm{kg} / \mathrm{m}^{2}$, and the mean BMI after 6 months diet intervention was $34.5 \pm 1.5(\mathrm{p}<0.05)$. Weight loss was achieved over a period of 6 months by a diet providing a daily energy deficit of 1,200 kcal/day. Diet adherence was monitored by daily food intake protocols.

In cohort 5 (mean baseline BMI $55.8 \pm 7.9 \mathrm{~kg} / \mathrm{m}^{2}$ ), 32 Caucasian obese volunteers (22 women, $10 \mathrm{men}$ ) participated in a prospective weight loss study before and 12 months after gastric sleeve resection or Rouxen-Y gastric bypass [14]. In a subgroup of 14 (10 females, 4 males) patients, omental and SC adipose tissue biopsies were obtained in the context of a two-step bariatric surgery strategy with gastric sleeve resection as the first step and a Roux-en-Y gastric bypass as second-step operation. The baseline BMI in this subgroup was $64.1 \pm 9.5 \mathrm{~kg} / \mathrm{m}^{2}$, and the BMI 12 months after bariatric surgery was $48.3 \pm 7.3 \mathrm{~kg} / \mathrm{m}^{2}$. Individuals of all cohorts fulfilled the previously described inclusion and exclusion criteria [14]. All study protocols have been approved by the ethics committee of the University of Leipzig. All participants gave written informed consent before taking part in the study.

Measurement of Body Fat Content, Glucose Metabolism, and Insulin Sensitivity

BMI was calculated as weight divided by squared height. Hip circumference was measured over the buttocks; waist circumference was measured at the midpoint between the lower ribs and iliac crest. Percentage body fat was measured by dual X-ray absorptiometry (DEXA). In cohort 2, abdominal visceral and SC fat areas were calculated using computed tomography (CT) scans at the level of L4-L5 in the cohort of paired visceral and SC adipose tissue donors. Three days before the OGTT, patients documented a high-carbohydrate diet in diet protocols. The OGTT was performed after an overnight fast with $75 \mathrm{~g}$ standardized glucose solution (Glucodex Solution 75 g; Merieux, Montreal, QC, Canada). Venous blood samples were taken at 0, 60, and 120 min for measurements of plasma glucose concentrations. Insulin sensitivity was assessed using the HOMA-IR index or with the euglycemic-hyperinsulinemic clamp method as described previously [18].

\section{Analyses of Blood Samples}

All baseline blood samples were collected between 8:00 and 10:00 a.m. after an overnight fast. Plasma insulin was measured with an enzyme immunometric assay for the IMMULITE automated analyzer (Diagnostic Products Corporation, Los Angeles, CA, USA). Serum high-sensitivity C-reactive protein (hsCrP) was measured as previously described [19]. Serum apelin-12 concentrations were measured with a commercial kit (Phoenix Pharmaceuticals, Burlingame, CA, USA) as per the manufacturer's protocol. The sensitivity of the assay was $0.2 \mathrm{ng} / \mathrm{ml}$. Prior to apelin measurements in human cohorts, we assessed the degree of precision of the ELISA system. The coefficient of variance of intra-assay was 5.3\%, and that of inter-assays was between 3.5 and $7.8 \%$ The ELISA has $100 \%$ cross-reactivity with human apelin-12, apelin-13, and apelin-36.

\section{Apelin and APJ mRNA Expression Studies}

Human apelin and APJ mRNA expression was measured by quantitative real-time RT-PCR in a fluorescent temperature cycler using the TaqMan assay, and fluorescence was detected on an ABI PRISM 7000 sequence detector (Applied Biosystems, Darmstadt, Germany). Total RNA was isolated using TRIzol (Life Technologies, Grand Island, NY, USA), and $1 \mu \mathrm{g}$ RNA was reverse transcribed with standard reagents (Life Technologies). From each RT-PCR, $2 \mu \mathrm{l}$ were amplified and in a $26-\mu \mathrm{l} \mathrm{PCR} \mathrm{using} \mathrm{the} \mathrm{Brilliant} \mathrm{SYBR} \mathrm{green} \mathrm{QPCR}$ Core reagent kit from Stratagene (La Jolla, CA, USA) according to the manufacturer's instructions. Samples were incubated in the ABI PRISM 7000 sequence detector for an initial denaturation at $95{ }^{\circ} \mathrm{C}$ for 10 min, followed by 40 PCR cycles, each cycle consisting of $95^{\circ} \mathrm{C}$ for $15 \mathrm{~s}, 60^{\circ} \mathrm{C}$ for $1 \mathrm{~min}$, and $72^{\circ} \mathrm{C}$ for $1 \mathrm{~min}$. Human apelin and APJ mRNA expression was calculated relative to the mRNA expression of $18 \mathrm{~s}$ rRNA, determined by a premixed assays on demand for apelin and APJ and 18s rRNA (Applied Biosystems). Amplification of specific transcripts was confirmed by melting curve profiles (cooling the sample to $68^{\circ} \mathrm{C}$ and heating slowly to $95^{\circ} \mathrm{C}$ with measurement of fluorescence) at the end of each PCR. The specificity of the PCR was further verified by subjecting the amplification products to agarose gel electrophoresis.

\section{Statistical Analyses}

Data are shown as means \pm SD unless stated otherwise. Before statistical analysis, non-normally distributed parameters were logarithmically transformed to approximate a normal distribution. The following statistical tests were used: paired Student's test, chi square test, and Pearson's simple correlation. Linear relationships were assessed by least square regression analysis. Statistical analysis was performed using SPSS version 12.0 (Chicago, IL, USA). P values $<0,05$ were considered to be statistically significant. 
Krist et al.: Effects of Weight Loss and Exercise on Apelin Serum Concentrations and Adipose Tissue Expression in Human Obesity

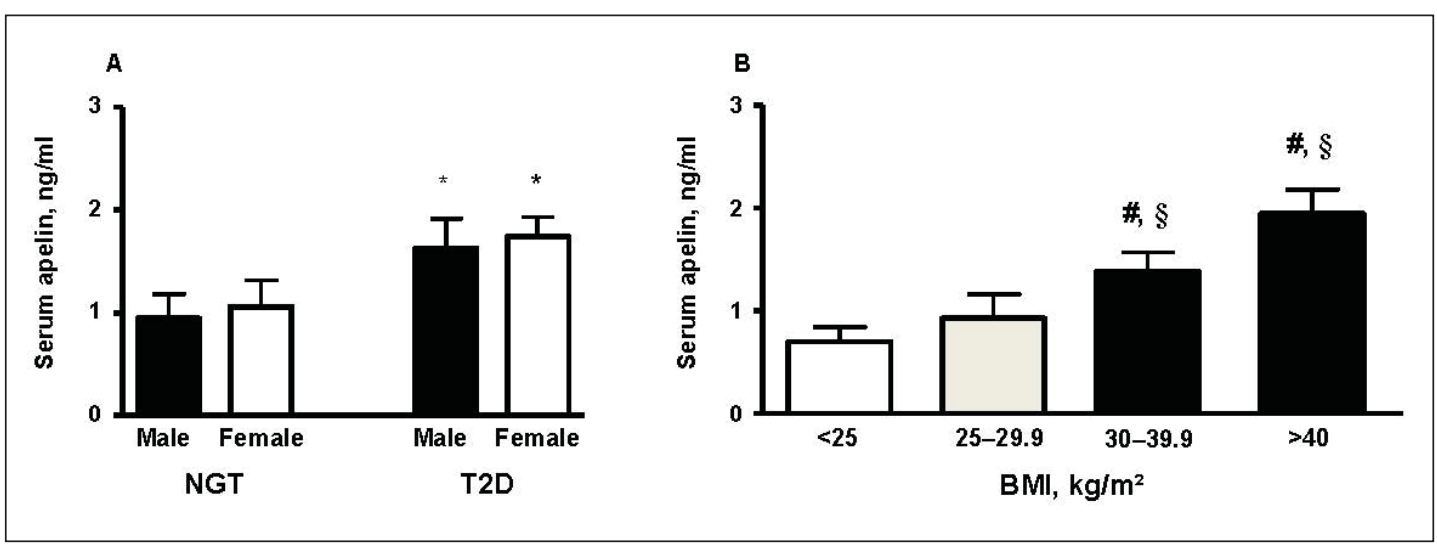

Fig. 1. Apelin serum concentration in NGT individuals and patients with T2D. A Circulating apelin in males $(n=93)$ and females $(n=85)$ with NGT and in males $(n=127)$ and females $(n=163)$ with T2D. B Apelin serum concentrations in lean (BMI $\left.<25 \mathrm{~kg} / \mathrm{m}^{2} ; \mathrm{n}=42\right)$, overweight (BMI $\left.>25-29.9 \mathrm{~kg} / \mathrm{m}^{2} ; \mathrm{n}=58\right)$ and obese (BMI $\left.>30 \mathrm{~kg} / \mathrm{m}^{2} ; \mathrm{n}=78\right)$ NGT subjects. ${ }^{*} \mathrm{p}<0.05$ adjusted for BMI compared to NGT within genders. ${ }^{\#} \mathrm{p}<$ 0.05 compared to BMI $<24.9 \mathrm{~kg} / \mathrm{m}^{2} ;{ }^{\S} \mathrm{p}<0.05$ compared to BMI $25-29.9 \mathrm{~kg} / \mathrm{m}^{2}$.

\section{Results}

\section{Apelin Serum Concentration in Obesity and T2D}

Anthropometric and metabolic characteristics of 468 individuals included in the crosssectional study (cohort 1) have been previously described [14]. Circulating apelin was not different between males and females with NGT and T2D (fig. 1A). Apelin serum concentration was approximately $60 \%$ higher in individuals with T2D as compared to those with NGT (fig. 1A) ( $p$ < 0.05). In age-, gender- and BMI-matched subgroups of NGT and T2D, we confirmed significantly higher apelin serum concentrations in T2D versus NGT. In addition, we found significantly higher apelin serum concentrations in obese patients with NGT as compared to both lean and overweight individuals (fig. 1B). In patients with T2D $(n=290)$, serum apelin concentration correlates with BMI $(r=0.35, \mathrm{p}<0.01)$. In 740 patients (representing the baseline apelin serum concentrations in cohorts 1-5) with a wide range of age, BMI, glucose tolerance and insulin sensitivity, we found significant relationships between circulating apelin and parameters of (abdominal) obesity, glucose and lipid metabolism, insulin sensitivity, and adipose tissue biology (table 2). Univariate regression analyses revealed significant correlations between apelin serum concentration and BMI, \% body fat, fasting plasma glucose, HbA1c, fasting plasma insulin (FPI), insulin sensitivity as determined by the glucose infusion rate (GIR) during the steady state of an euglycemic-hyperinsulinemic clamp, triglycerides, hsCrP as well as adipocyte size and number of macrophages in visceral adipose tissue (table 2). Correlations between circulating apelin and HbA1c, fasting plasma insulin, GIR, and hsCrP remained significant even after adjusting for BMI (table 2).

\section{Apelin and APJ mRNA Expression in Omental and SC Adipose Tissue}

We investigated apelin and APJ mRNA expression in visceral and SC adipose tissue in parallel with apelin serum concentrations in 161 previously described individuals [14], which have been classified into lean, predominantly subcutaneously obese or predominantly viscerally obese on the basis of abdominal visceral and SC fat area measurements using CT or MRI scans at the level of L4-L5 (cohort 2). In NGT individuals, apelin expression was not different between the omental and the SC fat depot, whereas in patients with T2D, apelin 
Krist et al.: Effects of Weight Loss and Exercise on Apelin Serum Concentrations and Adipose Tissue Expression in Human Obesity

Table 2. Univariate correlations (Spearman) between apelin serum concentration and apelin mRNA expression in omental and subcutaneous adipose tissue and measures of obesity, insulin sensitivity, and parameters of inflammation.

\begin{tabular}{|c|c|c|c|c|c|c|}
\hline & \multicolumn{2}{|c|}{$\begin{array}{l}\text { Serum apelin (baseline) } \\
\text { Cohorts } 1-5(n=740)\end{array}$} & \multicolumn{2}{|c|}{$\begin{array}{l}\text { Omental apelin mRNA } \\
\text { Cohort } 2(n=161)\end{array}$} & \multicolumn{2}{|c|}{$\begin{array}{l}\text { Subcutaneous apelin mRNA } \\
\text { Cohort } 2(n=161)\end{array}$} \\
\hline & $\mathrm{r}^{\mathrm{a}}$ & $\mathrm{p}$ value $\mathrm{a}^{\mathrm{a}}$ & $r^{\mathrm{a}}$ & $\mathrm{p}$ value $\mathrm{a}^{\mathrm{a}}$ & $\mathrm{r}^{\mathrm{a}}$ & $\mathrm{p}$ value $\mathrm{a}^{\mathrm{a}}$ \\
\hline Serum apelin & - & - & $0.42(0.31)$ & $<0.001(<0.001)$ & $0.26(0.19)$ & $<0.01(0.03)$ \\
\hline Age & 0.04 & ns & 0.02 & ns & 0.03 & ns \\
\hline Gender & 0.04 & ns & 0.02 & ns & 0.03 & ns \\
\hline BMI & $0.35(-)$ & $<0.01(-)$ & $0.41(-)$ & $<0.001(-)$ & $0.35(-)$ & $<0.001(-)$ \\
\hline$\%$ Body fat & $0.31(0.05)$ & $<0.01$ (ns) & $0.43(0.15)$ & $<0.001(0.04)$ & $0.4(0.1)$ & $<0.001$ (ns) \\
\hline Fasting plasma glucose & $0.19(0.07)$ & 0.04 (ns) & $0.05(0.01)$ & ns (ns) & $0.06(0.02)$ & ns (ns) \\
\hline $\mathrm{HbA1c}$ & $0.41(0.21)$ & $<0.001(0.01)$ & $0.39(0.17)$ & $<0.001(0.03 \mathrm{~ns})$ & $0.31(0.11)$ & $<0.01(\mathrm{~ns})$ \\
\hline Fasting plasma insulin & $0.56(0.18)$ & $<0.001(0.03)$ & $0.61(0.22)$ & $<0.001(<0.01)$ & $0.55(0.18)$ & $<0.001(<0.05)$ \\
\hline GIR & $-0.58(0.21)$ & $<0.001(0.02)$ & $-0.52(0.19)$ & $<0.001(<0.05)$ & $-0.39(0.11)$ & $<0.001(\mathrm{~ns})$ \\
\hline Triglycerides & $0.41(0.11)$ & $<0.001(\mathrm{~ns})$ & $0.38(0.1)$ & $<0.01(\mathrm{~ns})$ & $0.26(0.1)$ & $<0.01$ (ns) \\
\hline hsCrP & $0.29(0.21)$ & $<0.001(<0.05)$ & $0.39(0.24)$ & $<0.001(<0.01)$ & $0.29(0.18)$ & $<0.01(<0.05)$ \\
\hline Mean adipozyte size & $0.28(0.09)$ & $<0.001(\mathrm{~ns})$ & $0.33(0.1)$ & $<0.01(\mathrm{~ns})$ & $0.27(0.15)$ & $<0.01(\mathrm{~ns})$ \\
\hline $\begin{array}{l}\text { \% Macrophages in } \\
\text { adipose tissue }\end{array}$ & $0.19(0.080)$ & 0.03 (ns) & $0.37(0.21)$ & $<0.01(<0.01)$ & $0.1(0.04)$ & ns (ns) \\
\hline
\end{tabular}

GIR = Glucose infusion rate during the steady state of an euglycemic-hyperinsulinemic clamp; $r=$ Spearman's correlation coefficient; ns = not significant.

aValues in brackets are BMI-adjusted.

mRNA expression was significantly higher in omental compared to SC fat (fig. 2a). Moreover, apelin expression of both fat depots was about 2-fold higher in the T2D compared to the NGT group (fig. 2a). In age-, gender- and BMI-matched subgroups of NGT $(n=16)$ and T2D $(n=$ 16), we confirmed significantly higher apelin mRNA expression in both fat depots in T2D (omental 21.6 \pm 1.4 ; SC $18.2 \pm 1.5$ AU/18SrRNA) compared to NGT (omental $8.7 \pm 0.8$; SC 8.1 $\pm 0.35 \mathrm{AU} / 18 \mathrm{SrRNA}$ ). Lean individuals showed significantly lower apelin expression in visceral and SC adipose tissue compared to both subcutaneously and viscerally obese patients (fig. 2b). In addition, apelin expression (omental and SC) was significantly higher in viscerally compared to subcutaneously obese individuals. We found significant correlations of omental and SC apelin mRNA expression with apelin serum concentration and parameters of obesity, glycemic control, insulin sensitivity, inflammation, and adipose tissue biology (table 2). The correlations between omental apelin mRNA expression and serum apelin, number of macrophages in adipose tissue, hsCrP, GIR, HbA1c, \% body fat as well as FPI remained significant after adjusting for BMI (table 2). SC apelin mRNA expression only correlates with serum apelin, FPI, and hsCrP independently of BMI (table 2). In contrast to apelin, APJ mRNA expression was not significantly different between omental and SC adipose tissue both in NGT and T2D individuals (fig. 2c). There was a tendency for lower APJ mRNA expression in omental, but not SC adipose tissue in obese compared to lean individuals (fig. 2d).

\section{Changes in Apelin Serum Concentrations in Response to Different Weight Loss Interventions}

Serum apelin concentrations are significantly reduced after a 6-month hypocaloric diet intervention (cohort 4) (fig. 3a). Multivariate linear regression analyses identified changes in $\mathrm{BMI}$, insulin sensitivity and circulating hsCrP as significant predictors of changes in circulating apelin. Interestingly, only improved GIR are independently of changes in body weight associated with changes in apelin levels (table 3). 


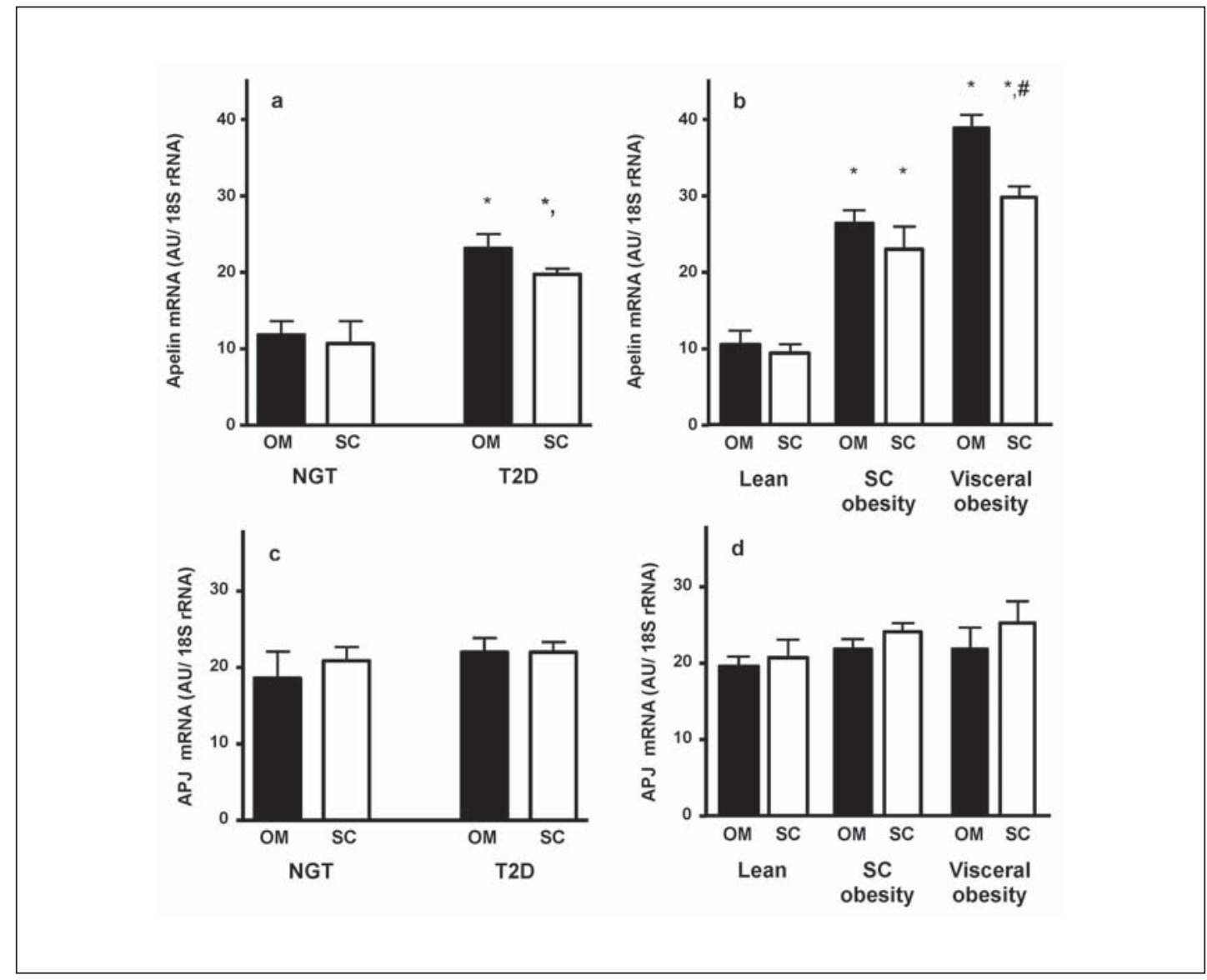

Fig. 2. Apelin and APJ mRNA expression in human omental (OM) and subcutaneous (SC) adipose tissue. a Apelin mRNA expression in the two different fat depots in NGT individuals $(n=116)$ and patients with T2D $(\mathrm{n}=45) .{ }^{*} \mathrm{p}<0.05$ adjusted for BMI compared to the NGT group; ${ }^{*} \mathrm{p}<0.05$ for the difference between OM and SC. $\mathbf{b}$ OM and SC apelin mRNA expression in lean, visceral obese and SC obese individuals. Abdominal visceral and SC fat areas were calculated using CT or MRI scans at the level of L4-L5 in the cohort of paired visceral and SC adipose tissue donors. SC obesity was defined as ratio of visceral to SC fat area $<0.4$. Visceral obesity was defined as ratio of visceral to SC fat area > 0.4. c APJ mRNA expression in the two different fat depots in NGT individuals $(n=116)$ and patients with T2D $(n=45)$. d OM and SC APJ mRNA expression in lean, visceral obese and SC obese individuals. Data are means \pm SEM. ${ }^{*} p<0.05$ compared to the lean group.

We further sought to dissect the effects of weight loss versus improved chronic glycemia and insulin sensitivity on apelin serum concentrations in the context of a 12-week exercise intervention (cohort 3). 60 Caucasian men and women completed a 12-week training program and were studied after being divided into subjects with NGT $(n=20)$, IGT $(n=20)$ as well as glucose tolerance or T2D ( $\mathrm{n}=20)$ as previously described [12]. Apelin serum concentration was significantly higher in individuals with IGT and T2D compared to those with NGT (fig. 3b). The training effect was confirmed by a significant improvement in $\mathrm{VO}_{2}$ max in all groups. 12 weeks of physical training resulted in significantly improved insulin sensitivity, HbA1c, and circulating hsCrP in the IGT and T2D groups despite the fact that BMI was not significantly changed. Apelin serum concentrations significantly decreased by approximately $20 \%$ in IGT and T2D subjects and by approximately 10\% in the NGT group after 12 weeks of the training program (fig. 3b). In accordance with the diet intervention data, multivariate linear regression 
Krist et al.: Effects of Weight Loss and Exercise on Apelin Serum Concentrations and

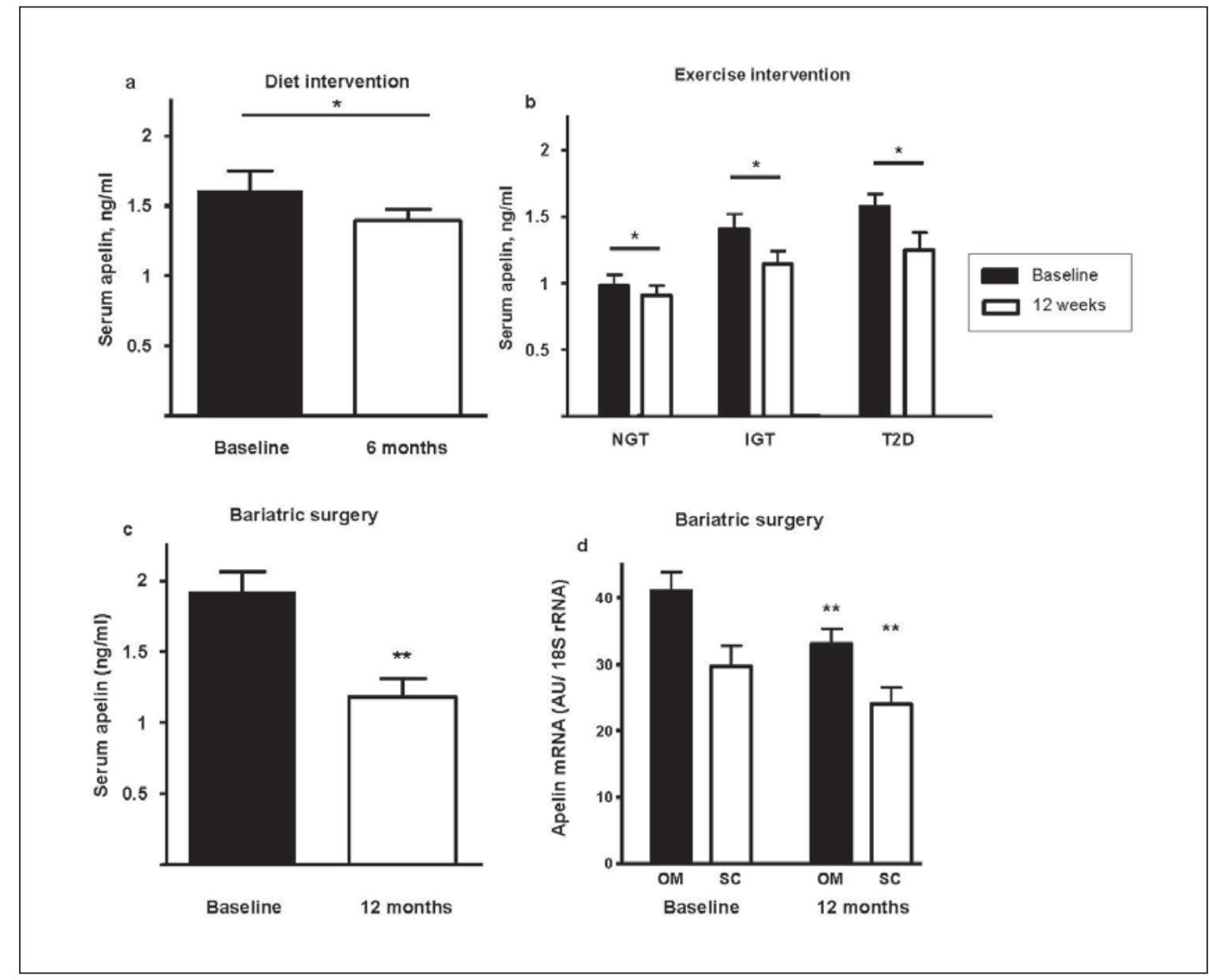

Fig. 3. Changes of apelin serum concentration in response to different weight loss interventions. a Effect of 6 months calorie-restricted diet, $\mathbf{b}$ effect of a 12 weeks exercise intervention, $\mathbf{c}$ effect of bariatric surgery on apelin serum concentration, and $\mathbf{d}$ apelin mRNA expression in omental adipose tissue. Data are means \pm SEM. $* \mathrm{p}<0.05$ adjusted for BMI compared to baseline.

analyses demonstrate that changes in GIR are independently of the BMI dynamic related to changes in apelin serum concentrations (table 3). In a third intervention study (cohort 5), we aimed to analyze changes in both apelin serum concentration and adipose tissue mRNA expression before and 12 months after obesity surgery. In response to bariatric surgery, we found significantly improved insulin sensitivity as measured by euglycemic-hyperinsulinemic clamps (GIR baseline $41 \pm 10.6 \mu \mathrm{mol} / \mathrm{kg} / \mathrm{min} ; 12$ months after surgery $78 \pm 17.2 \mu \mathrm{mol} / \mathrm{kg}$ / min; $\mathrm{p}<0.01$ ). Patients with morbid obesity have significantly higher apelin serum concentrations than all other investigated subgroups (fig. 3c). We found about $40 \%$ lower apelin serum concentrations 12 months after significant weight loss induced by bariatric surgery (fig. 3c). In parallel, we found in a subgroup of patients $(n=14)$ undergoing a two-step bariatric surgery strategy significantly reduced omental and SC apelin mRNA expression (fig. 3d). Multivariate regression analyses of changes in BMI, GIR, and hsCrP as predictors for changes in apelin serum concentrations demonstrate that changes in GIR and hsCrP are significantly associated with changes in apelin beyond the effects of body weight changes (table 2). 
Krist et al.: Effects of Weight Loss and Exercise on Apelin Serum Concentrations and Adipose Tissue Expression in Human Obesity

Table 3. Multivariate linear regression analysis of changes in different parameters as predictors of reduced apelin serum concentration in response to three different interventions (12 weeks exercise program, 6 months hypocaloric diet, 12 months after bariatric surgery)

\begin{tabular}{llll}
\hline & \multicolumn{2}{c}{$\Delta$ apelin serum concentration, $\beta$-coefficient $(\mathrm{p}$-value) } \\
\cline { 2 - 3 } & exercise intervention & hypocaloric diet & bariatric surgery \\
\hline Model 1 & & \\
Age & $0.03(0.91)$ & $0.02(0.95)$ & $0.04(0.83)$ \\
Gender & $0.04(0.88)$ & $0.04(0.89)$ & $0.04(0.8)$ \\
$\Delta$ BMI & $0.07(0.75)$ & $0.29(<0.01)$ & $0.45(<0.001)$ \\
\hline Model 2 & & \\
Age & $0.04(0.81)$ & $0.03(0.91)$ & $0.03(0.91)$ \\
Gender & $0.03(0.9)$ & $0.04(0.88)$ & $0.04(0.88)$ \\
$\Delta$ BMI & $0.05(0.84)$ & $0.11(0.2)$ & $0.22(<0.01)$ \\
$\Delta$ GIR & $-0.25(<0.01)$ & $-0.22(<0.01)$ & $-0.29(<0.01)$ \\
\hline Model 3 & & $0.05(0.86)$ & $0.04(0.88)$ \\
Age & $0.04(0.83)$ & $0.03(0.91)$ & $0.03(0.9)$ \\
Gender & $0.04(0.86)$ & $0.21(<0.05)$ & $0.28(<0.01)$ \\
$\Delta$ BMI & $0.1(0.31)$ & $0.11(0.1)$ & $0.21(<0.01)$ \\
$\Delta$ hsCrP & $0.14(0.08)$ & &
\end{tabular}

Changes of determinants of altered apelin serum concentrations were tested in three multivariate linear regression models. Changes in circulating apelin were adjusted for age and gender in each model. Changes in BMI explained 29\% (hypocaloric diet, $\mathrm{p}<0.01$ ) or $45 \%$ (bariatric surgery, $\mathrm{p}<0.001$ ) of the variation in circulating apelin (Model 1). In addition, we aimed to identify BMI-independent predictors of changes in circulating apelin by further adjusting $\Delta$ apelin for $\Delta$ BMI (Models 2 and 3). Model 2 revealed that changes in GIR significantly explained 25\% (exercise, $\mathrm{p}<0.01$ ), 22\% (hypocaloric diet, $\mathrm{p}<0.01$ ) or 29\% (bariatric surgery, $\mathrm{p}<0.01$ ) of the variation in circulating apelin (Model 2). Changes in circulating hsCrP explain 21\% of $\Delta$ apelin only in the bariatric surgery intervention in addition to significant changes in BMI (Model 3). Significant correlations are shown in italics.

GIR = Glucose infusion rate during the steady state of an euglycemic-hyperinsulinemic clamp.

\section{Discussion}

Changes in apelin serum concentrations after weight loss have been repeatedly reported [20-23]. However, some studies only found significantly reduced circulating apelin in subgroups of morbidly obese patients with impaired glucose metabolism in response to dramatic weight loss after bariatric surgery [22] or in moderately obese women, but not in patients with metabolic syndrome [20,21] or in obese children [23]. Moreover, circulating apelin levels do not necessarily correlate with body weight or fat mass [22-24]. On the other hand, apelin serum concentrations are significantly related to parameters of inflammation [21], glucose metabolism [22, 26], and insulin sensitivity [20, 27, 28]. Noteworthy, a variant in the apelin gene has been associated with plasma glucose concentrations in a large Chinese cohort [29].

We therefore sought to determine whether changes in apelin serum concentrations are primarily due to reduced body weight or reflect improved insulin sensitivity.

We confirmed previous findings that higher apelin serum concentrations in humans are associated with higher BMI as well as traits of the metabolic syndrome including high plasma glucose, triglycerides, and insulin resistance [6]. To address the controversy whether elevated 
Krist et al.: Effects of Weight Loss and Exercise on Apelin Serum Concentrations and Adipose Tissue Expression in Human Obesity

circulating apelin levels are primarily due to obesity, insulin resistance, hyperglycemia or inflammatory response, we measured the dynamic of apelin serum concentrations in three independent intervention studies. In all studies, we found significant BMI-independent correlations between reduced apelin levels and improved insulin sensitivity. There are at least two potential explanations for the association between circulating apelin and insulin sensitivity. First, reduced apelin serum concentrations may directly contribute to improved insulin sensitivity. Another conclusion could be that circulating apelin increases as a compensatory mechanism to improve insulin sensitivity which in turn may lead to decreased apelin levels. The latter hypothesis is supported by studies in apelin-deficient mice, in which supplementation of apelin causes significantly improved insulin sensitivity [8]. Apelin effects on insulin sensitivity may be direct via improved glucose uptake and intracellular insulin signaling [8] or indirect through improvements of energy metabolism including increased mitochondrial biogenesis and tighter matching between fatty acid oxidation and the tricarboxylic acid cycle [13].

In addition, in a bariatric surgery study reduction in apelin levels were BMI-independently associated with decreased hsCrP serum concentrations, suggesting that both insulin resistance and chronic inflammation may contribute to elevated apelin serum concentrations in patients with morbid obesity. Rubino et al. [30] have demonstrated that bypassing a short segment of the proximal intestine directly ameliorates T2D, independently of effects on food intake, body weight, or malabsorption in a rat model of diabetes. In our bariatric surgery intervention (cohort 5), we cannot exclude that changes in circulating apelin and insulin sensitivity occur independently of BMI, because we did not include post-surgery time points, where individuals did not yet significantly lose weight.

Two studies, a 6-month hypocaloric diet study and a bariatric surgery follow-up study, were designed to test the effects on circulating apelin achieved by significant weight loss. We show here that even moderate weight loss 6 months after a calorie-restricted diet significantly decreases apelin serum concentrations. The decrease in apelin levels can be explained by significantly improved insulin sensitivity. Interestingly, this association was independent of BMI changes, suggesting that changes in insulin sensitivity rather than fat mass reduction represent the mechanistic link between weight loss and lower apelin serum concentrations. Our data from the bariatric surgery study confirm previous findings that circulating apelin is significantly elevated in morbidly obese patients (reviewed in [2]) and can be significantly reduced by drastic reduction of BMI [22]. However, multivariate linear regression analyses demonstrated that, independently of these BMI changes, improved insulin sensitivity significantly predict changes in circulating apelin.

The third intervention, a 12-week exercise program, provided the opportunity to directly assess the effects of improved insulin sensitivity and reduced circulating inflammatory markers such as hsCrP in the absence of significant changes in BMI. We show here that improved GIR in euglycemic-hyperinsulinemic clamps, but not changes in hsCrP, correlate with reduced apelin levels despite the fact that BMI did not significantly change during the program. It has been recently shown that apelin inhibits insulin secretion and may therefore contribute to impaired glucose metabolism $[11,31]$. Since we did not assess insulin secretion directly, we cannot exclude that the relationship between apelin and insulin sensitivity is influenced by apelin effects on insulin secretion.

In accordance with recent reports, we found significantly higher apelin serum concentrations in patients with T2D (reviewed in [2]). In age-, gender- and BMI-matched subgroups of NGT and T2D, we demonstrate that these differences were independent of BMI. We extend previous findings by showing that elevated apelin serum concentrations may be due to significantly increased omental and SC adipose tissue apelin mRNA expression. Increased apelin expression in patients with T2D was more pronounced in the omental compared to the abdominal SC fat depot, suggesting a fat depot-specific regulation of apelin expression. We 
Krist et al.: Effects of Weight Loss and Exercise on Apelin Serum Concentrations and Adipose Tissue Expression in Human Obesity

found significantly higher apelin expression in omental compared to SC fat depots in T2D patients, whereas no apelin expression differences were observed in the NGT group. In a recent analysis of apelin and APJ mRNA expression both in skeletal muscle and abdominal SC adipose tissue from 28 individuals, there was only a trend for increased apelin expression in adipose tissue of T2D patients compared to healthy controls [26]. Noteworthy, we did not find any significant differences in the mRNA expression of the apelin receptor APJ between different fat depots, between individuals with NGT and T2D, or between lean and obese adipose tissue donors, suggesting that changes in adipose tissue function are primarily associated with changes in apelin and not APJ expression. In accordance with our data, Dray et al. [26] found no differences in APJ mRNA expression in adipose tissue of healthy control subjects and patients with T2D under basal conditions. Interestingly, the authors demonstrated that insulin stimulates APJ expression in skeletal muscle and adipose tissue of individuals with normal glucose metabolism, whereas in patients with T2D this effect was only found in skeletal muscle [26]. These data suggest that there are differences in the regulation of the apelin system between different insulin-sensitive tissues and that basal state expression of apelin and APJ may not necessarily represent the abnormalities of this system as a cause or response to impaired insulin sensitivity.

Our adipose tissue apelin expression studies further revealed significant BMI-independent associations between the omental apelin mRNA expression and serum apelin, number of macrophages in adipose tissue, hsCrP, GIR, HbA1c, \% body fat as well as FPI all of which remained significant after adjusting for BMI. SC apelin mRNA expression only correlates with serum apelin, FPI and hsCrP independently of BMI. In contrast to apelin, APJ mRNA expression was not significantly different in omental and SC adipose tissue. The correlation between omental apelin expression and macrophage infiltration suggests that immune cells may be a significant source of apelin production in adipose tissue and that circulating apelin may reflect adipose tissue inflammation and dysfunction [32]. A potential link between adipose tissue inflammation and elevated apelin secretion is further supported by the finding that TNF- $\alpha$ correlates with circulating apelin [21].

However, it is difficult to establish a causality chain whether adipose tissue inflammation cause increased apelin serum concentrations or whether increased apelin expression contributes to adipose tissue inflammation with subsequent insulin resistance and chronic inflammation. We further show that significantly increased apelin mRNA expression and circulating apelin in patients with morbid obesity can be significantly reduced by significant weight loss in response to obesity surgery. These data further suggest that adipose tissue apelin production significantly contributes to circulating apelin concentrations. This notion is supported by significant correlations between adipose tissue apelin mRNA expression and apelin serum concentrations.

In conclusion, we show here that impaired insulin sensitivity is a BMI-independent predictor of elevated apelin serum concentrations in obesity and obesity-associated insulin resistance. Increased apelin serum concentrations may reflect an intrinsic mechanism to compensate for insulin resistance, and lower apelin serum concentrations in healthy lean individuals may be a consequence rather than a cause of insulin sensitivity. Our data further suggest a role of apelin as potential marker of adipose tissue inflammation and support the notion that that reduced adipose tissue apelin expression may contribute to improved insulin sensitivity and subclinical inflammation beyond significant weight loss.

\section{Acknowledgements}

The authors would like to thank all study participants, Daniela Kox, Manuela Prellberg, and Susan Berthold for technical assistance. 
Krist et al.: Effects of Weight Loss and Exercise on Apelin Serum Concentrations and Adipose Tissue Expression in Human Obesity

\section{Funding}

This work was supported by the Federal Ministry of Education and Research (Competence network for Obesity: FKZ 01GI0829 and FKZ 01GI1128; IFB Adiposity Diseases: FKZ 01E01001, K7-19, K7-30) and a grant from Deutsche Forschungsgemeinschaft (DFG) the Clinical Research group 'Atherobesity' KFO 152 (project BL 833/1-1) (MB).

\section{Disclosure Statement}

The authors do not have any conflict of interest related to this manuscript. We disclose any financial conflict of interest.

\section{References}

- 1 Tatemoto K, Hosoya M, Habata Y, Fujii R, Kakegawa T, Zou MX, Kawamata Y, Fukusumi S, Hinuma S, Kitada C, Kurokawa T, Onda H, Fujino M: Isolation and characterization of a novel endogenous peptide ligand for the human APJ receptor. Biochem Biophys Res Commun 1998;251:471-476.

2 Castan-Laurell I, Dray C, Attané C, Duparc T, Knauf C, Valet P: Apelin, diabetes, and obesity. Endocrine 2011; 40:1-9.

3 Lee DK, Cheng R, Nguyen T, Fan T, Kariyawasam AP, Liu Y, Osmond DH, George SR, O’Dowd BF: Characterization of apelin, the ligand for the APJ receptor. J Neurochem 2000;74:34-41.

- 4 Castan-Laurell I, Boucher J, Dray C, Daviaud D, Guigné C, Valet P: Apelin, a novel adipokine over-produced in obesity: friend or foe? Mol Cell Endocrinol 2005;245, 7-9.

5 Tatemoto K: Search for an endogenous ligand of the orphan G protein-coupled receptor-discovery of apelin, a novel biologically active peptide. Nihon Rinsho 2000;58:737-46.

6 Boucher J, Masri B, Daviaud D, Gesta S, Guigné C, Mazzucotelli A, Castan-Laurell I, Tack I, Knibiehler B, Carpéné C, Audigier Y, Saulnier-Blache JS, Valet P. Apelin, a newly identified adipokine up-regulated by insulin and obesity. Endocrinology 2005;146:1764-1771.

7 Kuba K, Zhang L, Imai Y, Arab S, Chen M, Maekawa Y, Leschnik M, Leibbrandt A, Markovic M, Schwaighofer J, Beetz N, Musialek R, Neely GG, Komnenovic V, Kolm U, Metzler B, Ricci R, Hara H, Meixner A, Nghiem M, Chen X, Dawood F, Wong KM, Sarao R, Cukerman E, Kimura A, Hein L, Thalhammer J, Liu PP, Penninger JM: Impaired heart contractility in apelin gene-deficient mice associated with aging and pressure overload. Circ Res 2007; 101:e32-42.

8 Yue P, Jin H, Aillaud M, Deng AC, Azuma J, Asagami T, Kundu RK, Reaven GM, Quertermous T, Tsao PS: Apelin is necessary for the maintenance of insulin sensitivity. Am J Physiol Endocrinol Metab 2010;298:E59-E67.

- 9 Eyries M, Siegfried G, Ciumas M, Montagne K, Agrapart M, Lebrin F, Soubrier F: Hypoxia-induced apelin expression regulates endothelial cell proliferation and regenerative angiogenesis. Circ Res 2008;103:432440.

10 Principe A, Melgar-Lesmes P, Fernández-Varo G, del Arbol LR, Ros J, Morales-Ruiz M, Bernardi M, Arroyo V, Jiménez W: The hepatic apelin system: a new therapeutic target for liver disease. Hepatology 2008;48:11931201.

11 Sorhede Winzell, M, Magnusson, C, Ahren, B: The APJ receptor is expressed in pancreatic islets and its ligand, apelin, inhibits insulin secretion in mice. Regul Pept 2005;131:12-17.

-12 Dray C, Knauf C, Daviaud D, Waget A, Boucher J, Buléon M, Cani PD, Attané C, Guigné C, Carpéné C, Burcelin R, Castan-Laurell I, Valet P: Apelin stimulates glucose utilization in normal and obese insulin-resistant mice. Cell Metab 2008;8:437-445.

13 Attané C, Foussal C, Le Gonidec S, Benani A, Daviaud D, Wanecq E, Guzmán-Ruiz R, Dray C, Bezaire V, Rancoule C, Kuba K, Ruiz-Gayo M, Levade T, Penninger J, Burcelin R, Pénicaud L, Valet P, Castan-Laurell I: Apelin treatment increases complete fatty acid oxidation, mitochondrial oxidative capacity, and biogenesis in muscle of insulin-resistant mice. Diabetes 2012;61:310-320.

-14 Chakaroun R, Raschpichler M, Klöting N, Oberbach A, Flehmig G, Kern M, Schön MR, Shang E, Lohmann T, Dreßler M, Fasshauer M, Stumvoll M, Blüher M: Effects of weight loss and exercise on chemerin serum concentrations and adipose tissue expression in human obesity. Metabolism 2012;61:706-714.

-15 Harman-Boehm I, Blüher M, Redel H, Sion-Vardy N, Ovadia S, Avinoach E, Shai I, Klöting N, Stumvoll M, Bashan $\mathrm{N}$, Rudich A: Macrophage infiltration into omental versus subcutaneous fat across different populations: effect of regional adiposity and the comorbidities of obesity. J Clin Endocrinol Metab 2007;92:2240-2247.

16 Report of the Expert Committee on the Diagnosis and Classification of Diabetes Mellitus. Diabetes Care 2000; 23:S4-S19. 
Krist et al.: Effects of Weight Loss and Exercise on Apelin Serum Concentrations and

Adipose Tissue Expression in Human Obesity

17 Blüher M, Williams CJ, Klöting N, Hsi A, Ruschke K, Oberbach A, Fasshauer M, Berndt J, Schön MR, Wolk A, Stumvoll M, Mantzoros CS: Gene expression of adiponectin receptors in human visceral and subcutaneous adipose tissue is related to insulin resistance and metabolic parameters and is altered in response to physical training. Diabetes Care 2007;30:3110-3115.

18 Blüher M, Unger R, Rassoul F, Richter V, Paschke R: Relation between glycaemic control, hyperinsulinaemia and plasma concentrations of soluble adhesion molecules in patients with impaired glucose tolerance or type II diabetes. Diabetologia 2002;45:210-216.

19 Klöting N, Fasshauer M, Dietrich A, Kovacs P, Schön MR, Kern M, Stumvoll M, Blüher M: Insulin-sensitive obesity. Am J Physiol Endocrinol Metab 2010;299:E506-E515.

20 Castan-Laurell I, Vítkova M, Daviaud D, Dray C, Kováciková M, Kovacova Z, Hejnova J, Stich V, Valet P: Effect of hypocaloric diet-induced weight loss in obese women on plasma apelin and adipose tissue expression of apelin and APJ. Eur J Endocrinol 2008;158:905-910.

-21 Heinonen MV, Laaksonen DE, Karhu T, Karhunen L, Laitinen T, Kainulainen S, Rissanen A, Niskanen L, Herzig $\mathrm{KH}$ : Effect of diet-induced weight loss on plasma apelin and cytokine levels in individuals with the metabolic syndrome. Nutr Metab Cardiovasc Dis 2009;19:626-633.

22 Soriguer F, Garrido-Sanchez L, Garcia-Serrano S, Garcia-Almeida JM, Garcia-Arnes J, Tinahones FJ, GarciaFuentes E: Apelin levels are increased in morbidly obese subjects with type 2 diabetes mellitus. Obes Surg 2009;19:1574-1580.

-23 Reinehr T, Woelfle J, Roth CL: Lack of association between apelin, insulin resistance, cardiovascular risk factors, and obesity in children: a longitudinal analysis. Metabolism 2011;60:1349-1354.

24 Aydin S: The presence of the peptides apelin, ghrelin and nesfatin-1 in the human breast milk, and the lowering of their levels in patients with gestational diabetes mellitus. Peptides 2010;31:2236-2240.

-25 Telejko B, Kuzmicki M, Wawrusiewicz-Kurylonek N, Szamatowicz J, Nikolajuk A, Zonenberg A, Zwierz-Gugala D, Jelski W, Laudański P, Wilczynski J, Kretowski A, Gorska M: Plasma apelin levels and apelin/APJ mRNA expression in patients with gestational diabetes mellitus. Diabetes Res Clin Pract 2010;87:176-183.

26 Dray C, Debard C, Jager J, Disse E, Daviaud D, Martin P, Attané C, Wanecq E, Guigné C, Bost F, Tanti JF, Laville M, Vidal H, Valet P, Castan-Laurell I: Apelin and APJ regulation in adipose tissue and skeletal muscle of type 2 diabetic mice and humans. Am J Physiol Endocrinol Metab 2010;298:E1161-E1169.

-27 Li L, Yang G, Li Q, Tang Y, Yang M, Yang H, Li K: Changes and relations of circulating visfatin, apelin, and resistin levels in normal, impaired glucose tolerance, and type 2 diabetic subjects. Exp Clin Endocrinol Diabetes 2006; 114:544-548.

-28 Ercin CN, Dogru T, Tapan S, Kara M, Haymana C, Karadurmus N, Karslioglu Y, Acikel C: Plasma apelin levels in subjects with nonalcoholic fatty liver disease. Metabolism 2010;59:977-981.

29 Zhang R, Hu C, Wang CR, Ma XJ, Bao YQ, Xu J, Lu JY, Qin W, Xiang KS, Jia WP: Association of apelin genetic variants with type 2 diabetes and related clinical features in Chinese Hans. Chin Med J (Engl) 2009;122:12731276.

30 Rubino F, Forgione A, Cummings DE, Vix M, Gnuli D, Mingrone G, Castagneto M, Marescaux J: The mechanism of diabetes control after gastrointestinal bypass surgery reveals a role of the proximal small intestine in the pathophysiology of type 2 diabetes. Ann Surg 2006;244:741-749.

-31 Guo L, Li Q, Wang W, Yu P, Pan H, Li P, Sun Y, Zhang J: Apelin inhibits insulin secretion in pancreatic beta-cells by activation of PI3-kinase-phosphodiesterase 3B. Endocr Res 2009;34:142-154.

-32 Blüher M. Adipose tissue dysfunction in obesity. Exp Clin Endocrinol Diabetes 2009;117:241-250. 